\title{
Características da Resposta à Aids de Secretarias de Saúde, no Contexto da Política de Incentivo do Ministério da Saúde'
}

\section{Characteristics of the AIDS Response of Health Departments in the Context of the Incentive Policy of the Ministry of Health}

\author{
Alexandre Grangeiro \\ Especialista em Saúde Pública. Pesquisador Científico do Depar- \\ tamento de Medicina Preventiva da Faculdade de Medicina da \\ Universidade de São Paulo. \\ Endereço: Av. Dr. Arnaldo, 455, 20 Andar, CEP 01246-903, São \\ Paulo, SP, Brasil. \\ E-mail: ale.grangeiroळgmail.com

\section{Maria Mercedes Loureiro Escuder} \\ Mestre em Saúde Pública. Pesquisadora Científica do Instituto de \\ Saúde, Secretaria de Estado da Saúde de São Paulo. \\ Endereço: Rua Santo Antônio, 590, CEP 01314-000, São Paulo, SP, \\ Brasil. \\ E-mail: mmescuderœgmail.com
}

\section{Sara Romera da Silva}

Mestre em Saúde Pública. Médica Sanitarista do Centro de Referência e Treinamento DST/Aids. Secretaria de Estado da Saúde de São Paulo.

Endereço: Rua Santa Cruz, 81, CEP 04121-000, São Paulo, SP, Brasil. E-mail: sromeraœsaude.sp.gov.br

\section{Vilma Cervantes}

Especialista em Saúde Pública. Diretor Técnico de Divisão do Centro de Referência e Treinamento DST/Aids. Secretaria de Estado da Saúde de São Paulo.

Endereço: Rua Santa Cruz, 81, CEP 04121-000, São Paulo, SP, Brasil. E-mail: vilmaळcrt.saude.sp.gov.br

\section{Paulo Roberto Teixeira}

Especialista em Saúde Pública e Dermatologia. Médico Sanitarista e Assessor de Direção do Centro de Referência e Treinamento DST/ Aids. Secretaria de Estado da Saúde de São Paulo.

Endereço: Rua Santa Cruz, 81, CEP 04121-000, São Paulo, SP, Brasil.

E-mail: pteixeiraळsaude.sp.gov.br

I Financiamento: Departamento Nacional de DST, Aids e Hepatites Virais do Ministério da Saúde. Centro de Referência e Treinamento em DST/Aids, Secretaria de Estado da Saúde de São Paulo.

\section{Resumo}

Objetivos: Analisar a cobertura da Política de Incentivo do Ministério da Saúde para Programas de Aids e as características das ações de prevenção, assistência, gestão e apoio às organizações da sociedade civil induzidas nos Estados e municípios. Metodologia: Os Planos de Ações e Metas de 2006, das 27 Unidades Federadas e de 427 municípios incluídos na Política de Incentivo, foram analisados segundo indicadores estabelecidos para aferir a complexidade e a sustentabilidade das ações induzidas, a inclusão de populações prioritárias e a capacidade de intervenção na epidemia. Informações sobre população e casos de aids registrados foram utilizadas para mensurar a cobertura. Resultados: Os municípios incluídos representaram uma cobertura de $85,2 \%$ dos casos de aids do País. Houve uma baixa proporção de secretarias estaduais $(48,2 \%)$ e municipais $(32,6 \%)$ de saúde que contemplaram, concomitantemente, ações de prevenção para a população geral e as de maior prevalência da doença, assim como ações para o diagnóstico do HIV, o tratamento de pessoas infectadas e a prevenção da transmissão vertical. Em relação às populações prioritárias, 51,9\% dos Estados e 31,1\% dos municípios propuseram ações específicas na prevenção e na assistência. Estados (44,4\%) e municípios (27,9\%) com Planos abrangentes estão mais concentrados no Sudeste e em cidades de grande porte, representando a maioria dos casos de aids do País. Conclusão: A Política de Incentivo do Ministério da Saúde compreende as regiões de maior ocorrência da aids no Brasil, porém, o perfil da resposta induzida encontra-se parcialmente dissociado das características epidemiológicas da doença no País. 


\section{Palavras-chave: Aids; Prevenção de doenças; Avalia- ção de programas; Populações vulneráveis; Descen- tralização; Epidemiologia descritiva.}

\section{Abstract}

Objective: To analyze the coverage of the Brazilian Ministry of Health's Incentive Policy for AIDS programs and the characteristics of prevention, care, management and support to civil society organizations induced in states and municipalities. Methods: The 2006 Action and Target Plans of the 27 Brazilian States and 427 municipalities enlisted in the Incentive Policy were analyzed according to indicators established to measure the complexity and sustainability of actions taken, the inclusion of priority populations, and the ability to address the epidemic. Information on population and on AIDS cases that were reported was used to measure the coverage of the Incentive Policy. Results: The studied municipalities covered $85.2 \%$ of AIDS cases in the country. There was a low proportion of state $(48.2 \%)$ and municipal $(32.6 \%)$ departments that simultaneously adopted actions aimed at AIDS prevention in the general and in higher disease prevalence populations, as well as HIV diagnosis, treatment of infected individuals and mother-child transmission. Additionally, $51.9 \%$ of the states and $31.1 \%$ of the municipalities planned specific prevention and care actions aimed at priority population segments. States (44.4\%) and municipalities (27.9\%) with comprehensive responses are concentrated in the Southeast region, mainly in large cities, and represent most of the AIDS cases in the country. Conclusion: The Incentive Policy of the Ministry of Health comprises the regions with the highest incidences of AIDS, but the profile of the induced response is in partial disagreement with the epidemiological characteristics of the disease in Brazil. Keywords: AIDS; Disease prevention; Program Evaluation; Program Development; Vulnerable populations; Decentralization; Descriptive Epidemiology. 


\section{Introdução}

Desde o início do processo de reforma sanitária no Brasil, os municípios têm ocupado um papel de destaque no Sistema de Saúde, por serem, em seus territórios, os responsáveis diretos pela saúde da população, o que lhes impõe planejar e executar políticas de promoção e organizar a rede de serviços para o atendimento das demandas e necessidades da população. Para o fortalecimento desse papel, tem concorrido um grande número de políticas nacionais de descentralização, que, por meio de financiamento, diretrizes técnicas e formação de recursos humanos, buscaram transferir aos níveis locais uma parcela expressiva das atribuições e recursos que se encontravam sob responsabilidade federal e estadual, assim como induziram a adoção de modelos de atenção e de resposta a problemas locais de saúde (Escorel, 1999; Viana e Machado, 2009).

A política brasileira de aids, que teve início no Estado de São Paulo em 1983, foi fortemente influenciada por esse contexto (Grangeiro e col., 2009; Berkman e col., 2005), sendo que a descentralização (Grangeiro e col., 2010) cumpriu um papel estratégico para a implantação da resposta ao HIV, no âmbito do Sistema Único de Saúde (SUS) e nas regiões em que a doença assumiu um caráter epidêmico. Na política de descentralização desenvolvida nacionalmente destacam-se duas fases: a primeira, implementada entre 1994/2002, caracterizou-se por se basear em recursos de Acordos de Empréstimos com o Banco Mundial e envolveu as 27 Unidades Federadas e 150 municípios, selecionados por reunir mais de 70\% dos casos de aids do País (Banco Mundial, 2004).

A segunda fase surgiu como um aprimoramento da anterior e teve por finalidade substituir os recursos do Banco Mundial por fontes nacionais, adequar o financiamento da resposta à aids às normas do SUS e aumentar as atribuições e o grau de autonomia de Estados e municípios (Barboza, 2006; Pires, 2006; Taglieta, 2006, Grangeiro e col., 2010). Denominada Política de Incentivo no âmbito do Programa Nacional de DST/Aids (Brasil, 2002), esta etapa ampliou o número de municípios com programas estruturados, transferiu parcialmente para Estados a responsabilidade e os recursos para o financiamento das ações de organizações da sociedade civil (OSC) e reorganizou os princípios de gestão, vinculando o financiamento à definição de metas pactuadas entre gestores e movimentos sociais, ao cofinanciamento das ações e à obrigatoriedade da manutenção de equipes e estruturas voltadas para aids (Barboza, 2006; Pires, 2006; Taglieta, 2006).

Estudos para avaliar (Barboza, 2006; Pires, 2006; Taglieta, 2006; Fonseca e col., 2007; Duarte, 2008) os resultados dessa fase do processo de descentralização mostraram, como aspectos positivos, o aumento da sustentabilidade financeira, a ampliação da cobertura das ações e a substituição dos parâmetros de avaliação exclusivamente financeiros e administrativos por abordagens de caráter técnico. Por outro lado, observou-se, em parte dos Estados e municípios, baixo nível de execução técnica e financeira, uma possível redução do apoio às OSC e uma dissonância entre planejamento, informações epidemiológicas e prioridades programáticas nacionais.

Diante deste cenário, o Departamento Nacional de DST, Aids e Hepatites Virais do Ministério da Saúde (PN-DST/Aids) solicitou a realização de um novo estudo para avaliar a Política de Incentivo. A análise da cobertura da Política e das características da resposta induzida no âmbito dos Estados e municípios é apresentada neste artigo, o que inclui o estudo da abrangência das ações programáticas, a inclusão de populações prioritárias, a sustentabilidade financeira e a capacidade das secretarias de intervir na epidemia.

\section{Metodologia}

Foi realizado um estudo transversal de secretarias estaduais e municipais de saúde incluídas na Política de Incentivo até 31 de dezembro de 2006, para analisar as características das ações programáticas induzidas localmente, e aquelas incluídas até 31 de dezembro de 2008 para estimar a cobertura.

As taxas de cobertura foram estimadas com os dados do Departamento de Informática do SUS (DATASUS) (Ministério da Saúde, 2008). Para analisar o perfil das ações programáticas, utilizaram-se informações dos Planos de Ações e Metas (PAM) de Estados e municípios de 2006 (Programa Nacional 
de DST e AIDS, 2009), que foram revisados com base em um roteiro contendo as categorias de análise do estudo. O PAM constitui o instrumento de planejamento das secretarias, elaborados segundo normas do Ministério da Saúde. Indicadores geopolíticos para caracterizar os municípios foram obtidos do Instituto Brasileiro de Geografia e Estatística (2008) e do Programa das Nações Unidas para o Desenvolvimento (2007).

As taxas de cobertura da Política de Incentivo foram estimadas tendo em conta os casos de aids e a população brasileira. Para tanto, o total de casos registrados entre 2002 e 2006 , por categoria de transmissão e sexo, e a população residente nos municípios incluídos no Incentivo em 2008 foram divididos pelos números totais do Brasil.

As características das ações programáticas induzidas pela Política de Incentivo foram estudadas a partir das metas contidas nos PAM, que são o elemento estruturante dos Planos, das quais derivam as demais informações (Programa Nacional de DST e AIDS, 2009). Foram utilizados seis tipos de informações, que apresentam a seguinte estrutura hierárquica: (1) área de atuação $\rightarrow$ (2) meta $\rightarrow$ (3) diretrizes do PN-DST/Aids a qual se refere à meta (aqui denominada de "ação programática") $\rightarrow$ (4) especificação da meta/o quê? (denominado neste estudo de "finalidade da meta") $\rightarrow(5)$ população beneficiada $\rightarrow(6)$ recursos financeiros alocados.

A análise compreendeu três etapas: A primeira incluiu o estudo descritivo por área de atuação (1-Promoção, prevenção e proteção dos direitos; 2-Diagnóstico, tratamento e assistência; 3-Gestão e desenvolvimento humano e institucional e 4-Parcerias com OSC), especificando, separadamente, secretarias estaduais e municipais de saúde. Nessa análise, consideraram-se os recursos financeiros totais alocados em cada meta.

$\mathrm{Na}$ segunda etapa, as informações foram categorizadas em quatro dimensões: complexidade programática, inclusão de populações, poder de intervenção na epidemia e sustentabilidade local. Essas dimensões foram assim categorizadas:

(1) complexidade programática: definida segundo o conjunto de ações contempladas pelas metas, tendo sido considerados como "Estado/município com complexidade programática básica” aqueles que rea- lizaram, no mínimo a: (a) prevenção para populações específicas e (b) geral, (c) ampliação do diagnóstico da infecção pelo HIV, (d) atenção à saúde de pessoas com HIV (PVHIV) e (e) prevenção da transmissão vertical da sífilis e do HIV; como "Estado/município com maior complexidade programática" os que contemplaram, além do conjunto descrito acima, as ações de: (a) tratamento e diagnóstico das doenças sexualmente transmissíveis (DST), (b) redução do estigma e (c) ações de gestão e sustentabilidade; e como "Estado/município com complexidade programática parcial" aqueles que não contemplaram uma ou mais das ações categorizadas como "básica";

(2) a inclusão de populações foi categorizada como "resposta inclusiva" quando contemplados no PAM, concomitantemente, a assistência às PVHIV, portadores de DST, gestantes e crianças expostas; e, a prevenção em uma ou mais das populações com maior prevalência (profissionais do sexo, homens que fazem sexo com homens (HSH), travestis, transgêneros, usuários de drogas e de drogas injetáveis (UDI) e privados de liberdade). As secretarias que não contemplaram estes elementos foram categorizadas como de "resposta não inclusiva". Uma meta pode contemplar mais de uma população;

(3) poder de intervenção na epidemia: definido conforme a finalidade da meta, sendo consideradas como de "maior poder de intervenção" aquelas que objetivaram a oferta de serviços de prevenção e assistência diretamente à população. As demais, como aquisição de insumos e elaboração de material instrucional, foram classificadas como de "menor poder de intervenção”. A análise considerou os percentuais de recursos investidos em cada categoria;

(4) sustentabilidade financeira local da Política de Incentivo: definida a partir das áreas contempladas com recursos das secretarias, sendo categorizadas como "Política sustentável" as que alocaram recursos próprios na prevenção e assistência, e, como "pouco sustentáveis", aquelas que não previram recursos para uma dessas áreas.

Na terceira etapa da análise, os Estados e municípios foram classificados segundo o conjunto das dimensões analisadas na etapa anterior. Foram estabelecidas duas categorias: "Estados/municípios com respostas abrangentes" e Estados/municípios com respostas limitadas". Na primeira categoria, foram 
classificados aqueles que apresentaram quatro ou cinco das seguintes situações: (1) "complexidade programática básica" ou "de maior complexidade"; (2) inclusão de populações prioritárias na assistência e (3) na prevenção; (4) maior parcela dos recursos alocada em ações com "maior poder de intervenção" na assistência e prevenção; e (5) Política sustentável em âmbito local. As secretarias que apresentaram até três dessas situações foram incluídas na segunda categoria, a de "resposta limitada".

Os municípios classificados conforme a complexidade da resposta foram, então, analisados pelos seguintes indicadores: número absoluto e incidência média de aids por 100 mil habitantes (2002-2006); população residente (2006), macrorregião administrativa, inserção em regiões metropolitanas, interior ou capital, e Índice de Desenvolvimento Humano Municipal (IDH-M) (2005). Para essa análise, empregou-se a estatística de qui-quadrado para variáveis categóricas e, quando significantes (valores de $\mathrm{p}$ $<0,05)$, a análise de resíduos padronizados (Zres), assumindo como fora do padrão casos com valores acima de $|1,96|$ (Pereira, 2010). Para variáveis contínuas, utilizou-se ANOVA, recorrendo-se a Bonferroni para testar diferenças entre médias.

\section{Resultados}

\section{Cobertura da Política de Incentivo}

O conjunto de 481 municípios incluídos na Política de Incentivo até 2008 está constituído, fundamentalmente, pelos maiores centros urbanos do País, abrangendo $60,8 \%$ da população brasileira, 94,0\% dos municípios com mais de 100 mil habitantes e $42,9 \%$ das cidades de regiões metropolitanas. São municípios com IDH-M $(0,79)$ superior à média nacional, aproximando-se do limiar que caracteriza países de renda alta. A incidência média de aids nesses municípios, 24,3 casos por 100 mil habitantes, é 1,4 vezes superior à observada no Brasil e 3,7 vezes a de municípios não incluídos. As maiores taxas de cobertura populacional são observadas nas regiões Sudeste (76,8\%) e Centro Oeste (59,8\%) e as menores no Nordeste $(42,5 \%)$ e Norte $(42,9 \%)$. A cobertura é mais expressiva no contexto da epidemia, compreendendo $85,2 \%$ dos casos registrados no Brasil. Essa taxa variou de 90,4\% no Sudeste a
72,7\% no Nordeste.

Ao analisar as informações por categoria de transmissão, observa-se que a maior cobertura ocorreu para os casos registrados entre homo/bissexuais $(89,4 \%)$ e UDI $(88,5 \%)$, enquanto que o conjunto das relações heterossexuais, que inclui a maioria dos casos ocorridos em mulheres e em crianças infectadas, apresentou a menor taxa. Assim, 18,4\% dos casos ocorridos por transmissão vertical, $16,5 \%$ por transmissão heterossexual e 15,7\% entre mulheres foram observados nos mais de 5 mil municípios não incluídos no Incentivo.

Em 2006 foram destinados à Política de Incentivo R\$ 251,6 milhões, sendo 62,3\% para municípios e $37,8 \%$ para secretarias estaduais e Distrito Federal. Os recursos federais corresponderam a 75,0\%, a contrapartida estadual a $8,7 \%$ e a municipal a $16,2 \%$. $\mathrm{O}$ valor médio destinado aos Estados foi de R\$3,5 milhões e aos municípios R\$ 366,8 mil. As regiões Sul (R\$ 1,76/habitante) e Centro Oeste (R\$ 1,54/ habitante) foram as que apresentaram os maiores valores per capita, enquanto, o Nordeste (R\$ 357,11/ caso) e Norte (R\$338,44/caso) representaram os maiores valores por caso de aids.

\section{Áreas de atuação, ações programáticas, finalida- des e populações beneficiadas nos PAM}

A análise dos PAM por área de atuação mostrou que a maior proporção dos recursos previstos na Política de Incentivo está alocada na Gestão e no Desenvolvimento Humano e Institucional (aqui denominada área de gestão). Essa área representou 33,5\% dos recursos alocados na Política de Incentivo (Tabela 1). Para 32,6\% das secretarias (44,4\% estaduais e $22,2 \%$ municipais) os recursos alocados nesse componente foram superiores à somatória das áreas de Diagnóstico, Tratamento e Assistência e de Prevenção, Promoção e Proteção (aqui denominadas áreas de assistência e de prevenção).

Os investimentos na área de gestão foram dirigidos, especialmente, para metas vinculadas às ações programáticas de aprimoramento do processo de gestão (49,9\%) e atenção à saúde de PVHIV (35,2\%), presentes nos planos de $72,7 \%$ e $66,5 \%$ das secretarias, respectivamente. A maior proporção desses recursos foi dirigida a ações que tinham como população alvo os gestores de saúde (52,9\%), as PVHIV 
$(47,5 \%)$ e a população geral ( $47,5 \%)$, tendo como principais finalidades a contratação de trabalhadores, a aquisição de insumos e infraestrutura (29,5\%); a realização de eventos e treinamentos (22,7\%); e a execução de pesquisas, monitoramento e vigilância epidemiológica (10,0\%). Considerando os valores totais dos PAM, os recursos aplicados com essas finalidades representaram, respectivamente, o primeiro, terceiro e décimo montantes, com municípios investindo um maior volume de recursos com essas finalidades do que Estados. (Tabelas 1, 2 e 3).

Os valores vinculados à área de assistência (30,5\% do total do PAM), que foram predominantes nos Planos de 150 (33,0\%) secretarias (140 municipais e 10 estaduais) concentraram a maior proporção dos recursos de contrapartida (45,5\%) e estiveram alocados, principalmente, em metas com maior poder de intervenção na epidemia $(58,8 \%)$. As principais finalidades foram: atendimento à população e ampliação das ações desenvolvidas (28,5\%); implantação de serviços ou projetos e programas (14,9\%); disponibilidade de medicamentos (14,3\%); e testagem da população (9,9\%) (Tabela 1).

Chamou a atenção o fato de parte das secretarias não contemplarem, na área de assistência, metas específicas para a atenção à saúde de PVHIV (15,4\%), o diagnóstico e tratamento das DST $(41,0 \%)$, a prevenção da transmissão vertical da sífilis e do HIV $(44,7 \%)$ e o diagnóstico da infecção pelo $\operatorname{HIV}(62,1 \%)$ (Tabela 1). Essas ações não foram contempladas em nenhuma das áreas dos PAM de 4,0\%, 28,o\%, 14,8\% e $44,9 \%$ das secretarias, respectivamente. Assim, $53,4 \%$ das secretarias municipais e $29,6 \%$ das estaduais não incluíram metas que abrangessem, concomitantemente, PVHIV, portadores de DST, gestantes e crianças expostas.

Apesar de obrigatória, pelas normas pactuadas entre gestores do SUS, a aquisição de medicamentos para DST e doenças associadas à aids não estiveram presentes em 53,6\% dos Planos municipais e em 29,6\% dos estaduais (Tabelas 1, 2 e 3).

As metas da área de prevenção (27,5\% do total do PAM) caracterizaram-se por incluir, essencialmente, ações dirigidas às populações geral (91,0\% das secretarias e 50,8\% dos recursos) e específicas (83,3\% das secretarias e $34,3 \%$ dos recursos) e à profilaxia da transmissão vertical (56,6\% das secretarias e 9,3\% dos recursos). Foi reduzida a proporção de Estados e municípios que incluíram ações de prevenção realizadas no contexto da assistência (31,1\%), para a prevenção das doenças sexualmente transmissíveis (DST) $(18,5 \%)$ e para a redução do estigma $(14,1 \%)$ (Tabela 1).

As populações mais beneficiadas na prevenção foram a população geral, incluída em 93,2\% dos Planos, gestantes e crianças expostas, incluídas em 63,0\%, e jovens em escolas, incluídas em 51,3\%. Em contrapartida, populações com maior prevalência do HIV receberam menor atenção, sendo que homens e mulheres profissionais do sexo estiveram presentes em 39,9\% dos Planos, usuários de drogas em 32,4\%, HSH em 18,7\%, pessoas privadas de liberdade em $14,8 \%$ e travestis/transgêneros em 9,5\%. Em 165 municípios (38,6\%) e 6 Estados (22,2\%) não houve investimentos para estas populações. Os recursos destinados a essas populações representaram 2,2\% do valor dos Planos (Tabelas 1, 2 e 3). Mesmo somando a estes recursos os destinados às organizações da sociedade civil (OSC,) na sua totalidade, o valor dirigido às populações de maior prevalência chegariam a $10,7 \%$.

Pouco mais da metade (54,0\%) dos recursos investidos na prevenção tiveram por finalidade a realização de intervenções diretas na população, como a implantação de projetos/programas $(25,4 \%)$, a realização de ações educativas e/ou distribuição de preservativos (9,6\%) e a ampliação da cobertura das ações desenvolvidas (9,0\%). Ações de cunho informativo, como campanhas e materiais educativos, representaram 30,9\% dos gastos, constituindo o principal componente individual nessa área (Tabela 1). Consequentemente, $55,1 \%$ das secretarias concentraram os recursos de prevenção em metas que, isoladamente, possuem menor poder de intervenção, 41,0\% dos municípios não previram a aquisição de preservativos, fórmula infantil ou outros insumos de prevenção e 29,5\% (8 Estados e 126 municípios) não previram contrapartida nestas área (Tabelas 1 e 4).

As metas de estabelecer parceria com OSC ( $8,5 \%$ do total do PAM) restringiram-se aos planos estaduais (100\%) e aos recursos de fonte federal (99,0\%). A população priorizada para as ações com OSC difere, em certa medida, daquelas previstas nas demais áreas, sendo alvo populações vulneráveis 
Tabela I - Percentual de recursos e de secretarias estaduais, distrital e municipais de saúde qualificadas na Política de Incentivo do Ministério da Saúde para programas de aids segundo características das metas e as áreas de atuação. Brasil, 2006

\begin{tabular}{|c|c|c|c|c|c|c|c|c|c|c|}
\hline \multirow[t]{2}{*}{ Características } & \multicolumn{10}{|c|}{ Área de Atuação } \\
\hline & \multicolumn{2}{|c|}{ Gestão } & \multicolumn{2}{|c|}{ Assistência } & \multicolumn{2}{|c|}{ Prevenção } & \multicolumn{2}{|c|}{ OSC } & \multicolumn{2}{|c|}{ Total } \\
\hline Valor total (R\$ milhões**) & \multicolumn{2}{|c|}{84,3} & \multicolumn{2}{|c|}{76,7} & \multicolumn{2}{|c|}{69,2} & \multicolumn{2}{|c|}{21,4} & \multicolumn{2}{|c|}{251,7} \\
\hline & $\%$ & $\%$ & $\%$ & $\%$ & $\%$ & $\%$ & $\%$ & $\%$ & $\%$ & $\%$ \\
\hline Características das metas & recursos & cretari & ecursos & cretari & ecurso & cretari & recurso & cretar & ecurso & cretaria \\
\hline \multicolumn{11}{|l|}{ Origem dos recursos alocados } \\
\hline Federal & 76,9 & - & 62,7 & - & 79,0 & - & 99,0 & - & 75,0 & - \\
\hline Próprio & 23,1 & - & 37,3 & - & 21,0 & - & 1,0 & - & 25,0 & - \\
\hline \multicolumn{11}{|l|}{ Ações programáticas } \\
\hline Gestão e sustentabilidade & 49,9 & 72,7 & 5,2 & 7,3 & $\mathrm{I}, 2$ & 8,6 & 52,4 & 6,6 & 23,1 & 76,7 \\
\hline Atenção às pessoas com HIV & 35,2 & 66,5 & 54,2 & 84,6 & 5,4 & 31,1 & 6,1 & 2,9 & 30,3 & 96,0 \\
\hline Prevenção para população geral & 7,0 & 28,2 & 1,4 & 10,1 & 50,8 & 91,0 & 7,7 & 3,7 & 17,4 & 93,6 \\
\hline $\begin{array}{l}\text { Prevenção para populações } \\
\text { especificas }\end{array}$ & 4,1 & 18,1 & 1,9 & 10,8 & 34,3 & 83,3 & 11,2 & 9,9 & 12,3 & 88,8 \\
\hline Tratamento e diagnóstico das DST & 2,4 & 18,3 & 19,8 & 59,0 & 3,0 & 18,5 & - & - & 7,7 & 72,0 \\
\hline $\begin{array}{l}\text { Vigilância Epidemiológica, } \\
\text { monitoramento, avaliação e } \\
\text { pesquisas }\end{array}$ & 1,3 & 10,8 & 0,0 & 1,1 & 0,1 & 1,3 & - & - & 0,5 & 12,8 \\
\hline $\begin{array}{l}\text { Ampliação do diagnóstico da } \\
\text { infecção pelo HIV }\end{array}$ & 0,7 & 4,6 & 15,2 & 37,9 & 4,2 & 19,4 & 4,7 & 0,2 & 6,4 & 55,1 \\
\hline Fortalecimento e parcerias com OSC & 0,6 & 3,1 & - & - & 0,3 & 0,9 & 18,7 & 9,9 & 1,9 & 12,8 \\
\hline $\begin{array}{l}\text { Prevenção da transmissão vertical } \\
\text { da síflis e HIV }\end{array}$ & 0,3 & 7,9 & 9,5 & 55,3 & 9,3 & 56,6 & 0,0 & 0,2 & 5,5 & 85,2 \\
\hline $\begin{array}{l}\text { Tratamento e diagnóstico das } \\
\text { hepatites }\end{array}$ & 0,3 & 1,1 & 1,0 & 3,7 & 0,6 & 5,1 & - & - & 0,7 & 18,7 \\
\hline Redução do estigma e preconceito & 0,3 & 2,6 & 0,2 & 2,2 & 2,1 & 14,1 & 0,1 & 1,1 & 0,6 & 9,3 \\
\hline \multicolumn{11}{|l|}{ População beneficiada } \\
\hline $\begin{array}{l}\text { Gestores e coordenadores de } \\
\text { programas de DST e aids }\end{array}$ & 52,9 & 85,5 & 2,9 & 7,5 & 0,9 & 7,5 & 0,3 & 1,1 & 18,9 & 87,7 \\
\hline População geral & 47,5 & 77,3 & 23,9 & 55,5 & 57,3 & 93,2 & 12,5 & 9,3 & 40,0 & 99,6 \\
\hline Pessoas vivendo com HIV & 47,5 & 79,3 & 55,3 & 85,7 & 8,6 & 30,8 & 55,8 & 15,4 & 39,9 & 98,2 \\
\hline Portadores de DST & 35,7 & 68,5 & 28,5 & 70,0 & 3,4 & 15,0 & 50,4 & 7,5 & 25,9 & 93,2 \\
\hline Usuários de serviços de saúde & 34,5 & 58,6 & 5,2 & 19,6 & 4,4 & 19,4 & 4,7 & 1,3 & 14,7 & 70,7 \\
\hline Profissional de saúde & 20,5 & 64,5 & 2,9 & 13,2 & 2,5 & 21,8 & 0,1 & 0,4 & 8,5 & 72,7 \\
\hline $\begin{array}{l}\text { Populações vulneráveis } \\
\text { (garimpo, índio etc.) }\end{array}$ & 15,3 & 37,9 & 3,5 & 8,1 & 23,5 & 44,3 & 78,4 & 14,8 & 19,3 & 65,2 \\
\hline Membros de OSC & 3,8 & 10,1 & 0,9 & 0,4 & 1,1 & 3,7 & 69,4 & 10,1 & 7,8 & 18,7 \\
\hline Gestantes & 1,3 & 6,4 & 9,7 & 57,5 & 9,4 & 56,6 & 0,0 & 0,2 & 6,0 & 84,4 \\
\hline Crianças expostas & 1,3 & 16,3 & 12,1 & 68,7 & 8,8 & 59,5 & 0,2 & 0,4 & 6,5 & 92,1 \\
\hline Outros Profissionais & 0,9 & 5,7 & 0,3 & 0,4 & $\mathrm{I}, 7$ & 17,0 & 0,1 & 0,2 & 0,9 & 21,6 \\
\hline Portadores de hepatites & 0,6 & 3,5 & 1,2 & 3,5 & 0,2 & 1,1 & 0,0 & 0,2 & 0,6 & 7,5 \\
\hline
\end{tabular}


Tabela I - Percentual de recursos e de secretarias estaduais, distrital e municipais de saúde qualificadas na Política de Incentivo do Ministério da Saúde para programas de aids segundo características das metas e as áreas de atuação. Brasil, 2006 (continuação)

\begin{tabular}{|c|c|c|c|c|c|c|c|c|c|c|}
\hline \multirow[t]{2}{*}{ Características } & \multicolumn{10}{|c|}{ Área de Atuação } \\
\hline & \multicolumn{2}{|c|}{ Gestão } & \multicolumn{2}{|c|}{ Assistência } & \multicolumn{2}{|c|}{ Prevenção } & \multicolumn{2}{|c|}{ OSC } & \multicolumn{2}{|c|}{ Total } \\
\hline Valor total (R\$ milhões**) & \multicolumn{2}{|c|}{84,3} & \multicolumn{2}{|c|}{76,7} & \multicolumn{2}{|c|}{69,2} & \multicolumn{2}{|c|}{21,4} & \multicolumn{2}{|r|}{251,7} \\
\hline & $\%$ & $\%$ & $\%$ & $\%$ & $\%$ & $\%$ & $\%$ & $\%$ & $\%$ & $\%$ \\
\hline Características das metas & recursos & secretarias & recursos & secretarias & recursos & secretarias & recursos & secretarias & recursos & s secretarias \\
\hline Escola e comunidade escolar & 0,5 & 7,5 & - & 0,0 & 6,9 & 51,3 & 0,7 & 0,9 & 2,1 & 57,0 \\
\hline Jovens fora da escola & 0,3 & 2,4 & 0,2 & 1,5 & 4,8 & 22,9 & 0,9 & 1,3 & 1,6 & 25,6 \\
\hline Usuários de Drogas e UDI & 0,3 & 2,6 & 0,0 & 0,7 & 6,8 & 32,4 & 1,3 & 2,6 & 2,1 & 34,8 \\
\hline $\begin{array}{l}\text { Portadores de necessidades } \\
\text { especiais }\end{array}$ & 0,2 & 0,7 & 0,0 & 0,7 & 0,6 & 4,2 & - & - & 0,3 & 5,1 \\
\hline Portadores de TB & 0,2 & 0,2 & 0,2 & 1,3 & 0,1 & 0,4 & - & - & 0,2 & 2,0 \\
\hline $\begin{array}{l}\text { Profissionais do sexo masculino } \\
\text { e feminino }\end{array}$ & 0,2 & 2,9 & 0,1 & 1,1 & 6,1 & 39,9 & 2,7 & 3,1 & 2,0 & 44,5 \\
\hline Mulheres & 0,2 & 1,5 & 1,5 & 3,7 & 4,0 & 17,6 & 0,0 & 0,7 & 1,6 & 22,0 \\
\hline Vítimas de violência sexual & 0,1 & 1,5 & 0,5 & 4,0 & 0,1 & 3,1 & - & - & 0,2 & 8,4 \\
\hline $\begin{array}{l}\text { Privados de liberdade adultos e } \\
\text { jovens }\end{array}$ & 0,1 & 1,1 & 0,0 & 1,3 & 3,0 & 14,8 & - & - & 0,9 & 16,7 \\
\hline Baixa renda & 0,1 & 2,0 & 0,2 & 0,2 & 2,0 & 6,4 & - & - & 0,6 & 8,4 \\
\hline Conselheiros de saúde & 0,1 & 2,0 & - & 0,0 & 0,0 & 1,3 & - & - & 0,0 & 3,3 \\
\hline Gay, homossexuais e HSH & 0,1 & $\mathrm{I}, 8$ & - & 0,0 & 4,3 & 18,7 & 3,0 & 2,4 & 1,5 & 21,4 \\
\hline Trabalhadores & 0,1 & 0,9 & - & 0,0 & 0,6 & 6,6 & - & - & 0,2 & 7,3 \\
\hline Travestis e transgêneros & 0,1 & 0,9 & 0,2 & 0,2 & 2,9 & 9,5 & 2,0 & 1,3 & 1,0 & 11,2 \\
\hline Idoso & 0,1 & 0,7 & - & 0,0 & 0,9 & 8,1 & 0,0 & 0,4 & 0,3 & 9,0 \\
\hline Caminhoneiro & 0,0 & 0,7 & 0,1 & 0,2 & 0,9 & 9,9 & 0,1 & 0,4 & 0,3 & 11,0 \\
\hline Negros & - & - & - & 0,0 & 0,6 & 2,2 & $\mathrm{I}, \mathrm{I}$ & 0,2 & 0,3 & 2,4 \\
\hline Finalidade da meta & & & & & & & & & & \\
\hline $\begin{array}{l}\text { Contratação de RH, material de } \\
\text { consumo e infraestrutura }\end{array}$ & 29,5 & 59,7 & 8,6 & 18,5 & 1,2 & 4,6 & 0,6 & 0,7 & 12,9 & 67,6 \\
\hline Eventos e treinamentos & 22,7 & 81,3 & 3,6 & 18,5 & 7,0 & 47,8 & 0,2 & $\mathrm{I}, \mathrm{I}$ & 10,6 & 91,9 \\
\hline $\begin{array}{l}\text { Vigilância epidemiológica, } \\
\text { monitoramento, avaliação, } \\
\text { pesquisa e sistema de informação }\end{array}$ & 10,0 & 36,1 & 2,0 & 2,9 & 0,2 & 3,5 & 0,0 & 0,4 & 4,0 & 47,8 \\
\hline $\begin{array}{l}\text { Disponibilização de } \\
\text { medicamentos de DST e IO }\end{array}$ & 8,4 & 21,8 & 14,3 & 29,1 & 0,2 & 1,3 & - & - & 7,2 & 33,0 \\
\hline $\begin{array}{l}\text { Implementação de serviços } \\
\text { assistenciais e aconselhamento }\end{array}$ & 4,6 & 6,4 & 4,8 & 23,3 & $\mathrm{I}, \mathrm{I}$ & 6,2 & - & - & 3,3 & 39,0 \\
\hline Execução do PAM & 4,0 & 5,1 & 0,1 & 0,2 & - & - & - & - & 1,4 & 5,3 \\
\hline $\begin{array}{l}\text { Aquisição de preservativos, } \\
\text { Fórmula e kit de redução de } \\
\text { danos }\end{array}$ & 3,5 & 18,1 & 3,8 & 30,2 & 4,7 & 23,8 & 0,2 & 0,4 & 3,6 & 61,5 \\
\hline $\begin{array}{l}\text { Transferência de recursos para } \\
\text { municipios e OSC }\end{array}$ & 3,2 & 5,1 & 0,0 & 0,2 & 0,5 & 0,7 & 57,3 & 5,7 & 6,1 & 9,9 \\
\hline
\end{tabular}


Tabela I - Percentual de recursos e de secretarias estaduais, distrital e municipais de saúde qualificadas na Política de Incentivo do Ministério da Saúde para programas de aids segundo características das metas e as áreas de atuação. Brasil, 2006 (continuação)

\begin{tabular}{|c|c|c|c|c|c|c|c|c|c|c|}
\hline Características & & & & & Área & ttuaçã & & & & \\
\hline & & stão & Ass & incia & & 1ção & & & & \\
\hline Valor total (R\$ milhões**) & & 4,3 & & & & & & & & 1,7 \\
\hline & $\%$ & $\%$ & $\%$ & $\%$ & $\%$ & $\%$ & $\%$ & $\%$ & $\%$ & $\%$ \\
\hline Características das metas & recursos & secretar & recursos & cretari & recurso & cretar & ecurso & cretar & ecurs & ccretari \\
\hline $\begin{array}{l}\text { Ação educativa e distribuição de } \\
\text { preservativo }\end{array}$ & 3,2 & 14,1 & 0,6 & 2,6 & 9,6 & 43,4 & 0,0 & 0,2 & 3,9 & 53,5 \\
\hline $\begin{array}{l}\text { Implantação de serviços } \\
\text { assistenciais e CTA }\end{array}$ & 2,4 & $\mathrm{II}, 7$ & 7,6 & 26,9 & 3,1 & 15,9 & 0,1 & 0,2 & 4,0 & 44,7 \\
\hline $\begin{array}{l}\text { Implantação de projetos e } \\
\text { programas }\end{array}$ & 2,2 & 10,4 & 7,3 & 30,2 & 25,4 & 61,7 & 0,0 & 0,4 & 10,0 & 74,7 \\
\hline $\begin{array}{l}\text { Atendimento à população, } \\
\text { ampliação de cobertura de ações }\end{array}$ & I,8 & 4,6 & 28,5 & 65,6 & 9,0 & 46,7 & 0,0 & 0,2 & $\mathrm{II}, 8$ & 80,8 \\
\hline $\begin{array}{l}\text { Parceria com secretarias e outros } \\
\text { órgãos }\end{array}$ & ।,6 & 3,3 & 0,3 & 0,9 & 0,1 & 1,3 & - & - & 0,6 & 4,8 \\
\hline Projetos de OSC & 1,0 & 7,7 & 0,1 & 1,1 & 2,0 & 4,8 & 41,5 & 21,6 & 4,4 & 31,7 \\
\hline $\begin{array}{l}\text { Implantação e melhorias de } \\
\text { laboratórios de DST, aids e } \\
\text { hepatites }\end{array}$ & 0,8 & 2,2 & 6,7 & 26,9 & 0,8 & 9,9 & - & - & 2,5 & 32,4 \\
\hline $\begin{array}{l}\text { Campanhas, material educativo } \\
\text { e outras formas de informação à } \\
\text { população }\end{array}$ & 0,5 & 3,5 & 0,2 & 2,0 & 30,9 & 85,2 & 0,0 & 0,2 & 8,7 & 86,3 \\
\hline Outros & 0,2 & 3,5 & 0,0 & 0,9 & 0,5 & 4,8 & 0,0 & 0,4 & 0,2 & 9,5 \\
\hline Pessoas testadas para o HIV & 0,1 & 1,8 & 9,9 & 21,6 & 3,7 & 15,2 & - & - & 4,1 & 36,6 \\
\hline Controle Social & 0,1 & 0,9 & & 2,0 & 0,0 & 0,2 & - & - & 0,0 & 1,3 \\
\hline $\begin{array}{l}\text { Normas/protocolos/ } \\
\text { recomendações }\end{array}$ & 0,1 & 1,3 & 1,6 & 18,5 & 0,1 & 1,1 & - & - & 0,5 & 4,4 \\
\hline $\begin{array}{l}\text { Recursos aplicados em ações com } \\
\text { maior poder de intervenção da } \\
\text { epidemia }\end{array}$ & 15,4 & - & 58,8 & - & 54,0 & - & 41,7 & - & 41,5 & - \\
\hline
\end{tabular}


Tabela 2 - Percentual de recursos alocados e de secretarias de estado qualificadas na Política de Incentivo do Ministério da Saúde para programas de aids segundo características das metas e áreas de atuação. Brasil, 2006

\begin{tabular}{|c|c|c|c|c|c|c|c|c|c|c|}
\hline \multirow[t]{2}{*}{ Características } & \multicolumn{10}{|c|}{ Área de Atuação } \\
\hline & \multicolumn{2}{|c|}{ Gestão } & \multicolumn{2}{|c|}{ Assistência } & \multicolumn{2}{|c|}{ Prevenção } & \multicolumn{2}{|r|}{ OSC } & \multicolumn{2}{|c|}{ Total } \\
\hline Valor total dos recursos (R\$ milhões) & \multicolumn{2}{|c|}{33,2} & \multicolumn{2}{|c|}{24,3} & \multicolumn{2}{|r|}{19,7} & \multicolumn{2}{|r|}{17,9} & \multicolumn{2}{|r|}{95,0} \\
\hline & $\%$ & $\%$ & $\%$ & $\%$ & $\%$ & $\%$ & $\%$ & $\%$ & $\%$ & $\%$ \\
\hline Características das metas & recursos & secretarias & recursos & secretarias & recursos & secretarias & recursos & secretarias & recursos & secretarias \\
\hline \multicolumn{11}{|l|}{ Origem dos recursos alocados } \\
\hline Federal & 79,7 & - & 55,2 & - & 78,7 & - & 99,6 & - & 76,9 & - \\
\hline Próprio & 20,3 & - & 44,8 & - & 21,3 & - & 0,4 & - & 23,1 & - \\
\hline \multicolumn{11}{|l|}{ Ações programáticas } \\
\hline Gestão e sustentabilidade & 52,1 & 100,0 & 4,9 & 11,1 & $\mathrm{I}, 8$ & 22,2 & 57,8 & 29,6 & 30,7 & 100,0 \\
\hline Atenção às pessoas com HIV & 32,2 & 66,7 & 69,8 & 96,3 & 3,7 & 29,6 & 3,8 & 11,1 & 30,6 & 100,0 \\
\hline Prevenção para população geral & 7,0 & 33,3 & 0,7 & 22,2 & 59,0 & 92,6 & 6,5 & 14,8 & 16,1 & 92,6 \\
\hline $\begin{array}{l}\text { Prevenção para populações } \\
\text { específicas }\end{array}$ & 4,5 & 33,3 & 0,6 & 11,1 & 39,2 & 92,6 & 7,0 & 14,8 & 11,2 & 92,6 \\
\hline Tratamento e diagnóstico das DST & 1,3 & 18,5 & 18,2 & 66,7 & 2,9 & 22,2 & - & - & 5,7 & 70,4 \\
\hline $\begin{array}{l}\text { Vigilância Epidemiológica, } \\
\text { monitoramento, avaliação e } \\
\text { pesquisas }\end{array}$ & 2,0 & 37,0 & 0,0 & 3,7 & 0,2 & 3,7 & - & - & 0,8 & 40,7 \\
\hline $\begin{array}{l}\text { Ampliação do diagnóstico da } \\
\text { infecção pelo HIV }\end{array}$ & 0,1 & 3,7 & 9,5 & 63,0 & 4,0 & 25,9 & 5,6 & 3,7 & 4,3 & 81,5 \\
\hline Fortalecimento e parcerias com OSC & 0,6 & 18,5 & - & - & - & - & 19,3 & 44,4 & 3,8 & 48,1 \\
\hline $\begin{array}{l}\text { Prevenção da transmissão vertical } \\
\text { da síflis e HIV }\end{array}$ & 0,4 & $\mathrm{II}, \mathrm{I}$ & 4,9 & 63,0 & 8,1 & 55,6 & - & - & 3,1 & 92,6 \\
\hline $\begin{array}{l}\text { Tratamento e diagnóstico das } \\
\text { hepatites }\end{array}$ & 0,0 & 3,7 & 0,6 & 3,7 & 1,2 & 7,4 & - & - & 0,4 & 14,8 \\
\hline Redução do estigma e preconceito & 0,3 & 7,4 & 0,3 & 7,4 & 2,6 & 25,9 & - & - & 0,7 & 33,3 \\
\hline \multicolumn{11}{|l|}{ População beneficiada } \\
\hline $\begin{array}{l}\text { Gestores e coordenadores de } \\
\text { programas de DST e aids }\end{array}$ & 54,4 & 96,3 & 5,3 & 14,8 & 1,4 & 25,9 & 0,0 & 3,7 & 36,5 & 100,0 \\
\hline População geral & 48,5 & 88,9 & 15,4 & 70,4 & 65,8 & 96,3 & 10,5 & 14,8 & 46,4 & 100,0 \\
\hline Pessoas vivendo com HIV & 48,3 & 100,0 & 63,2 & 92,6 & 13,5 & 59,3 & 56,0 & 44,4 & 34,5 & 96,3 \\
\hline Portadores de DST & 45,1 & 88,9 & 29,6 & 85,2 & 4,0 & 33,3 & 55,3 & 37,0 & 31,4 & 92,6 \\
\hline Usuários de serviços de saúde & 32,5 & 66,7 & 3,1 & 7,4 & 4,7 & 18,5 & 5,6 & 3,7 & 20,6 & 96,3 \\
\hline Profissional de saúde & 15,8 & 81,5 & 3,0 & 29,6 & 1,9 & 25,9 & 0,1 & 3,7 & 14,2 & 74,1 \\
\hline $\begin{array}{l}\text { Populações vulneráveis } \\
\text { (garimpo, índio etc.) }\end{array}$ & 21,9 & 74,1 & ।,8 & 22,2 & 37,0 & 74,1 & 83,2 & 77,8 & 6,7 & 92,6 \\
\hline Membros de OSC & 5,2 & 48,1 & 2,9 & 3,7 & 2,9 & 22,2 & 79,2 & 63,0 & 18,0 & 74,1 \\
\hline Gestantes & ।,8 & 25,9 & 5,7 & 63,0 & 9,1 & 55,6 & - & - & 4,6 & 100,0 \\
\hline Crianças expostas & 2,3 & 33,3 & 9,8 & 85,2 & 6,3 & 59,3 & - & - & 4,0 & 92,6 \\
\hline Outros Profissionais & 1,0 & 14,8 & 0,0 & 3,7 & 0,6 & 18,5 & 0,1 & 3,7 & 0,8 & 66,7 \\
\hline Portadores de hepatites & 0,5 & 7,4 & - & - & - & - & - & - & 0,8 & 48,1 \\
\hline
\end{tabular}


Tabela 2 - Percentual de recursos alocados e de secretarias de estado qualificadas na Política de Incentivo do Ministério da Saúde para programas de aids segundo características das metas e áreas de atuação. Brasil, 2006 (continuação)

\begin{tabular}{|c|c|c|c|c|c|c|c|c|c|c|}
\hline \multirow[t]{2}{*}{ Características } & \multicolumn{10}{|c|}{ Área de Atuação } \\
\hline & \multicolumn{2}{|c|}{ Gestão } & \multicolumn{2}{|c|}{ Assistência } & \multicolumn{2}{|c|}{ Prevenção } & \multicolumn{2}{|c|}{ OSC } & \multicolumn{2}{|c|}{ Total } \\
\hline Valor total dos recursos (R\$ milhões) & \multicolumn{2}{|c|}{33,2} & \multicolumn{2}{|c|}{24,3} & \multicolumn{2}{|c|}{19,7} & \multicolumn{2}{|r|}{17,9} & \multicolumn{2}{|r|}{95,0} \\
\hline \multirow[b]{2}{*}{ Características das metas } & $\%$ & $\%$ & $\%$ & $\%$ & $\%$ & $\%$ & $\%$ & $\%$ & $\%$ & $\%$ \\
\hline & recursos & secretari & recursos & secretaric & recurso & secretaric & recursos & secretar & recursc & secretari \\
\hline Escola e comunidade escolar & - & - & - & - & 3,9 & 66,7 & - & - & 0,6 & 33,3 \\
\hline Jovens fora da escola & 0,3 & 3,7 & - & - & 3,5 & 29,6 & 0,8 & 7,4 & 0,4 & 22,2 \\
\hline Usuários de Drogas e UDI & 0,1 & 7,4 & - & - & 3,9 & 44,4 & - & - & 1,0 & 40,7 \\
\hline $\begin{array}{l}\text { Portadores de necessidades } \\
\text { especiais }\end{array}$ & 0,5 & 7,4 & - & - & 0,1 & 7,4 & - & - & 0,7 & 29,6 \\
\hline Portadores de TB & 0,4 & 3,7 & 0,3 & 3,7 & - & - & - & - & 0,8 & 29,6 \\
\hline $\begin{array}{l}\text { Profissionais do sexo masculino } \\
\text { e feminino }\end{array}$ & 0,0 & 3,7 & - & - & 1,1 & 22,2 & $\mathrm{I}, 8$ & 7,4 & 1,0 & 37,0 \\
\hline Mulheres & - & - & 0,6 & 7,4 & 1,3 & 18,5 & - & - & 0,5 & 29,6 \\
\hline Vítimas de violência sexual & - & - & 0,7 & 14,8 & - & - & - & - & 0,5 & 22,2 \\
\hline $\begin{array}{l}\text { Privados de liberdade adultos e } \\
\text { jovens }\end{array}$ & 0,2 & 3,7 & - & - & 4,5 & 33,3 & - & - & 0,2 & 7,4 \\
\hline Baixa renda & 0,2 & 7,4 & 0,6 & 3,7 & $\mathrm{I}, 2$ & 11,1 & - & - & 0,1 & 14,8 \\
\hline Conselheiros de saúde & 0,2 & 7,4 & - & - & 0,0 & 3,7 & - & - & 0,2 & 14,8 \\
\hline Gay, homossexuais e HSH & 0,0 & 3,7 & - & - & $\mathrm{I}, 0$ & 18,5 & 2,5 & $\mathrm{II}, \mathrm{I}$ & 0,3 & $\mathrm{II}, \mathrm{I}$ \\
\hline Trabalhadores & - & - & - & - & 0,4 & 11,1 & - & - & 0,1 & 11,1 \\
\hline Travestis e transgêneros & 0,0 & 3,7 & 0,5 & 3,7 & 1,5 & 18,5 & $\mathrm{I}, 8$ & 7,4 & 0,2 & 14,8 \\
\hline Idoso & 0,0 & 3,7 & - & - & 0,4 & 7,4 & - & - & 0,1 & 11,1 \\
\hline Caminhoneiro & - & - & - & - & 0,4 & 14,8 & - & - & 0,2 & 7,4 \\
\hline Negros & - & - & - & - & 0,3 & 7,4 & 1,3 & 3,7 & 0,1 & $\mathrm{II}, \mathrm{I}$ \\
\hline \multicolumn{11}{|l|}{ Finalidade da meta } \\
\hline $\begin{array}{l}\text { Contratação de RH, material de } \\
\text { consumo e infraestrutura }\end{array}$ & 18,7 & 63,0 & 8,7 & 29,6 & 0,6 & 7,4 & - & - & 8,9 & 74,1 \\
\hline Eventos e treinamentos & 18,8 & 92,6 & 4,1 & 40,7 & 6,4 & 59,3 & 0,1 & 3,7 & 8,9 & 92,6 \\
\hline $\begin{array}{l}\text { Vigilância epidemiológica, } \\
\text { monitoramento, avaliação, } \\
\text { pesquisa e sistema de informação }\end{array}$ & 13,6 & 85,2 & 0,4 & 7,4 & - & - & 0,0 & 3,7 & 4,9 & 85,2 \\
\hline $\begin{array}{l}\text { Disponibilização de } \\
\text { medicamentos de DST e } 10\end{array}$ & 11,4 & 29,6 & 28,6 & 40,7 & - & - & - & - & 11,3 & 70,4 \\
\hline $\begin{array}{l}\text { Implementação de serviços } \\
\text { assistenciais e aconselhamento }\end{array}$ & 10,5 & 14,8 & 2,2 & 18,5 & 1,1 & 7,4 & - & - & 4,5 & 40,7 \\
\hline Execução do PAM & 7,1 & $\mathrm{II}, \mathrm{I}$ & - & - & - & - & - & - & 2,5 & $\mathrm{II}, \mathrm{I}$ \\
\hline $\begin{array}{l}\text { Aquisição de preservativos, } \\
\text { Fórmula e kit de redução de } \\
\text { danos }\end{array}$ & 5,0 & 22,2 & 7,7 & 70,4 & 5,8 & 40,7 & - & - & 4,9 & 100,0 \\
\hline $\begin{array}{l}\text { Transferência de recursos para } \\
\text { municípios e OSC }\end{array}$ & 4,2 & 29,6 & 0,1 & 3,7 & 0,9 & 7,4 & 67,4 & 51,9 & 14,3 & 66,7 \\
\hline
\end{tabular}


Tabela 2 - Percentual de recursos alocados e de secretarias de estado qualificadas na Política de Incentivo do Ministério da Saúde para programas de aids segundo características das metas e áreas de atuação. Brasil, 2006 (continuação)

\begin{tabular}{|c|c|c|c|c|c|c|c|c|c|c|}
\hline \multirow{4}{*}{$\begin{array}{l}\text { Características } \\
\text { Valor total dos recursos (R\$ milhões) } \\
\end{array}$} & \multicolumn{10}{|c|}{ Área de Atuação } \\
\hline & \multicolumn{2}{|c|}{ Gestão } & \multicolumn{2}{|c|}{ Assistência } & \multicolumn{2}{|c|}{ Prevenção } & \multicolumn{2}{|c|}{ OSC } & \multicolumn{2}{|c|}{ Total } \\
\hline & \multicolumn{2}{|c|}{33,2} & \multicolumn{2}{|c|}{24,3} & \multicolumn{2}{|c|}{19,7} & \multicolumn{2}{|c|}{17,9} & \multicolumn{2}{|c|}{95,0} \\
\hline & $\%$ & $\%$ & $\%$ & $\%$ & $\%$ & $\%$ & $\%$ & $\%$ & $\%$ & $\%$ \\
\hline \multicolumn{11}{|l|}{ Características das metas } \\
\hline $\begin{array}{l}\text { Ação educativa e distribuição de } \\
\text { preservativo }\end{array}$ & 3,0 & $\mathrm{II}, \mathrm{I}$ & - & - & 2,9 & 22,2 & - & - & 1,6 & 33,3 \\
\hline $\begin{array}{l}\text { Implantação de serviços } \\
\text { assistenciais e CTA }\end{array}$ & 0,9 & 22,2 & 6,0 & 48,1 & 4,1 & 22,2 & 0,1 & 3,7 & 2,7 & 63,0 \\
\hline $\begin{array}{l}\text { Implantação de projetos e } \\
\text { programas }\end{array}$ & 0,6 & 14,8 & 1,0 & 25,9 & 32,7 & 74,1 & - & - & 7,2 & 85,2 \\
\hline $\begin{array}{l}\text { Atendimento à população, } \\
\text { ampliação de cobertura de ações }\end{array}$ & 0,4 & 7,4 & 25,5 & 51,9 & 8,9 & 40,7 & - & - & 8,5 & 63,0 \\
\hline $\begin{array}{l}\text { Parceria com secretarias e outros } \\
\text { órgãos }\end{array}$ & 3,6 & 7,4 & - & - & - & - & - & - & 1,3 & 7,4 \\
\hline Projetos de OSC & 1,1 & 29,6 & - & - & 3,6 & 14,8 & 32,4 & 51,9 & 7,2 & 81,5 \\
\hline $\begin{array}{l}\text { Implantação e melhorias de } \\
\text { laboratórios de DST, aids e } \\
\text { hepatites }\end{array}$ & - & - & 3,8 & 33,3 & 0,1 & 7,4 & - & - & 1,0 & 33,3 \\
\hline $\begin{array}{l}\text { Campanhas, material educativo } \\
\text { e outras formas de informação à } \\
\text { população }\end{array}$ & 0,9 & 18,5 & 0,2 & 3,7 & 31,2 & 81,5 & - & - & 6,8 & 85,2 \\
\hline Outros & 0,2 & 11,1 & 0,2 & 3,7 & 0,4 & 3,7 & - & - & 0,2 & 18,5 \\
\hline Pessoas testadas para o HIV & - & - & 6,9 & 37,0 & 1,3 & 11,1 & - & & 2,0 & 44,4 \\
\hline Controle Social & 0,1 & 3,7 & 0,4 & 7,4 & - & - & - & - & 0,0 & 3,7 \\
\hline $\begin{array}{l}\text { Normas/protocolos/ } \\
\text { recomendações }\end{array}$ & 0,0 & 3,6 & 4,7 & 29,6 & - & - & - & - & 1,2 & 11,1 \\
\hline $\begin{array}{l}\text { Recursos aplicados em ações com } \\
\text { maior poder de intervenção da } \\
\text { epidemia }\end{array}$ & 16,7 & - & 41,7 & - & 54,4 & - & 32,5 & - & 33,9 & - \\
\hline
\end{tabular}


Tabela 3 - Percentual de recursos e de secretarias municipais de saúde qualificadas na Política de Incentivo do Ministério da Saúde para programas de aids segundo características das metas e áreas de atuação. Brasil, 2006

\begin{tabular}{|c|c|c|c|c|c|c|c|c|c|c|}
\hline \multirow[t]{2}{*}{ Características } & \multicolumn{10}{|c|}{ Área de Atuação } \\
\hline & \multicolumn{2}{|c|}{ Gestão } & \multicolumn{2}{|c|}{ Assistência } & \multicolumn{2}{|c|}{ Prevenção } & \multicolumn{2}{|c|}{ OSC } & \multicolumn{2}{|r|}{ Total } \\
\hline Valor total dos recursos (R\$ milhões) & \multicolumn{2}{|c|}{51,2} & \multicolumn{2}{|c|}{52,4} & \multicolumn{2}{|c|}{49,5} & \multicolumn{2}{|r|}{3,6} & \multicolumn{2}{|r|}{156,6} \\
\hline & $\%$ & $\%$ & $\%$ & $\%$ & $\%$ & $\%$ & $\%$ & $\%$ & $\%$ & $\%$ \\
\hline Características das metas & recursos & secretarias & recursos & secretarias & recursos & secretarias & recursos & secretarias & recursos & s secretarias \\
\hline \multicolumn{11}{|l|}{ Origem dos recursos alocados } \\
\hline Federal & 75,1 & - & 66,3 & - & 79,1 & - & 96,4 & - & 73,9 & - \\
\hline Próprio & 24,9 & - & 33,7 & - & 20,9 & - & 3,6 & - & 26,1 & - \\
\hline \multicolumn{11}{|l|}{ Ações programáticas } \\
\hline Gestão e sustentabilidade & 48,5 & 71,0 & 5,3 & 7,0 & 0,9 & 7,7 & 25,2 & 5,2 & 18,5 & 75,2 \\
\hline Atenção às pessoas com HIV & 37,2 & 66,5 & 46,9 & 83,8 & 6,0 & 31,1 & 17,4 & 2,3 & 30,1 & 95,8 \\
\hline Prevenção para população geral & 7,0 & 27,9 & 1,7 & 9,4 & 47,6 & 90,9 & 14,0 & 3,0 & 18,2 & 93,7 \\
\hline $\begin{array}{l}\text { Prevenção para populações } \\
\text { específicas }\end{array}$ & 3,8 & 17,1 & 2,6 & 10,8 & 32,4 & 82,7 & 32,0 & 9,6 & 13,1 & 88,5 \\
\hline Tratamento e diagnóstico das DST & 3,2 & 18,3 & 20,5 & 58,5 & 3,1 & 18,3 & - & 0,0 & 8,9 & 72,1 \\
\hline $\begin{array}{l}\text { Vigilância Epidemiológica, } \\
\text { monitoramento, avaliação e } \\
\text { pesquisas }\end{array}$ & 0,9 & 9,1 & 0,0 & 0,9 & 0,1 & 1,2 & - & - & 0,3 & 11,0 \\
\hline $\begin{array}{l}\text { Ampliação do diagnóstico da } \\
\text { infecção pelo HIV }\end{array}$ & 1,1 & 4,7 & 17,8 & 36,3 & 4,3 & 19,0 & - & - & 7,7 & 53,4 \\
\hline Fortalecimento e parcerias com OSC & 0,6 & 2,1 & - & - & 0,4 & 0,9 & 15,9 & 7,7 & 0,7 & 10,5 \\
\hline $\begin{array}{l}\text { Prevenção da transmissão vertical } \\
\text { da síflis e HIV }\end{array}$ & 0,3 & 7,7 & 11,6 & 54,8 & 9,7 & 56,7 & 0,1 & 0,2 & 7,1 & 84,8 \\
\hline $\begin{array}{l}\text { Tratamento e diagnóstico das } \\
\text { hepatites }\end{array}$ & 0,5 & 0,9 & 1,2 & 3,7 & 0,4 & 4,9 & - & - & 0,8 & 17,8 \\
\hline Redução do estigma e preconceito & 0,3 & 2,3 & 0,2 & 1,9 & 1,9 & 13,3 & 0,9 & 1,2 & 0,7 & 8,9 \\
\hline \multicolumn{11}{|l|}{ População beneficiada } \\
\hline $\begin{array}{l}\text { Gestores e coordenadores de } \\
\text { programas de DST e aids }\end{array}$ & 52,0 & 84,8 & 1,7 & 7,0 & 0,7 & 6,3 & 1,7 & 0,9 & 17,8 & 87,1 \\
\hline População geral & 46,9 & 76,6 & 27,8 & 54,6 & 54,0 & 93,0 & 22,2 & 8,9 & 42,2 & 99,5 \\
\hline Pessoas vivendo com HIV & 46,9 & 78,0 & 51,7 & 85,2 & 6,6 & 29,0 & 54,8 & 13,6 & 36,0 & 98,1 \\
\hline Portadores de DST & 29,6 & 67,2 & 28,0 & 69,1 & 3,2 & 13,8 & 26,2 & 5,6 & 20,6 & 93,0 \\
\hline Usuários de serviços de saúde & 35,8 & 58,1 & 6,1 & 20,4 & 4,2 & 19,4 & 0,3 & $\mathrm{I}, 2$ & 15,1 & 70,5 \\
\hline Profissional de saúde & 23,5 & 63,5 & 2,9 & 12,2 & 2,7 & 21,5 & 0,3 & 0,2 & 9,5 & 71,4 \\
\hline $\begin{array}{l}\text { Populações vulneráveis } \\
\text { (garimpo, índio etc.) }\end{array}$ & 10,9 & 35,6 & 4,3 & 7,3 & 18,1 & 42,4 & 54,3 & 10,8 & 12,0 & 63,5 \\
\hline Membros de OSC & 3,0 & 7,7 & 0,4 & 0,2 & 0,4 & 2,6 & 20,8 & 6,8 & 1,6 & 15,2 \\
\hline Gestantes & 1,0 & 5,2 & 11,6 & 57,1 & 9,6 & 56,7 & 0,1 & 0,2 & 7,2 & 83,8 \\
\hline Crianças expostas & 0,7 & 15,2 & 13,1 & 67,7 & 9,7 & 59,5 & 1,0 & 0,5 & 7,7 & 91,6 \\
\hline Outros Profissionais & 0,8 & 5,2 & 0,4 & 0,2 & 2,2 & 16,9 & - & - & $\mathrm{I}, \mathrm{I}$ & 21,1 \\
\hline Portadores de hepatites & 0,7 & 3,3 & I,7 & 3,7 & 0,2 & 1,2 & 0,0 & 0,2 & 0,9 & 7,5 \\
\hline
\end{tabular}


Tabela 3 - Percentual de recursos e de secretarias municipais de saúde qualificadas na Política de Incentivo do Ministério da Saúde para programas de aids segundo características das metas e áreas de atuação. Brasil, 2006 (continuação)

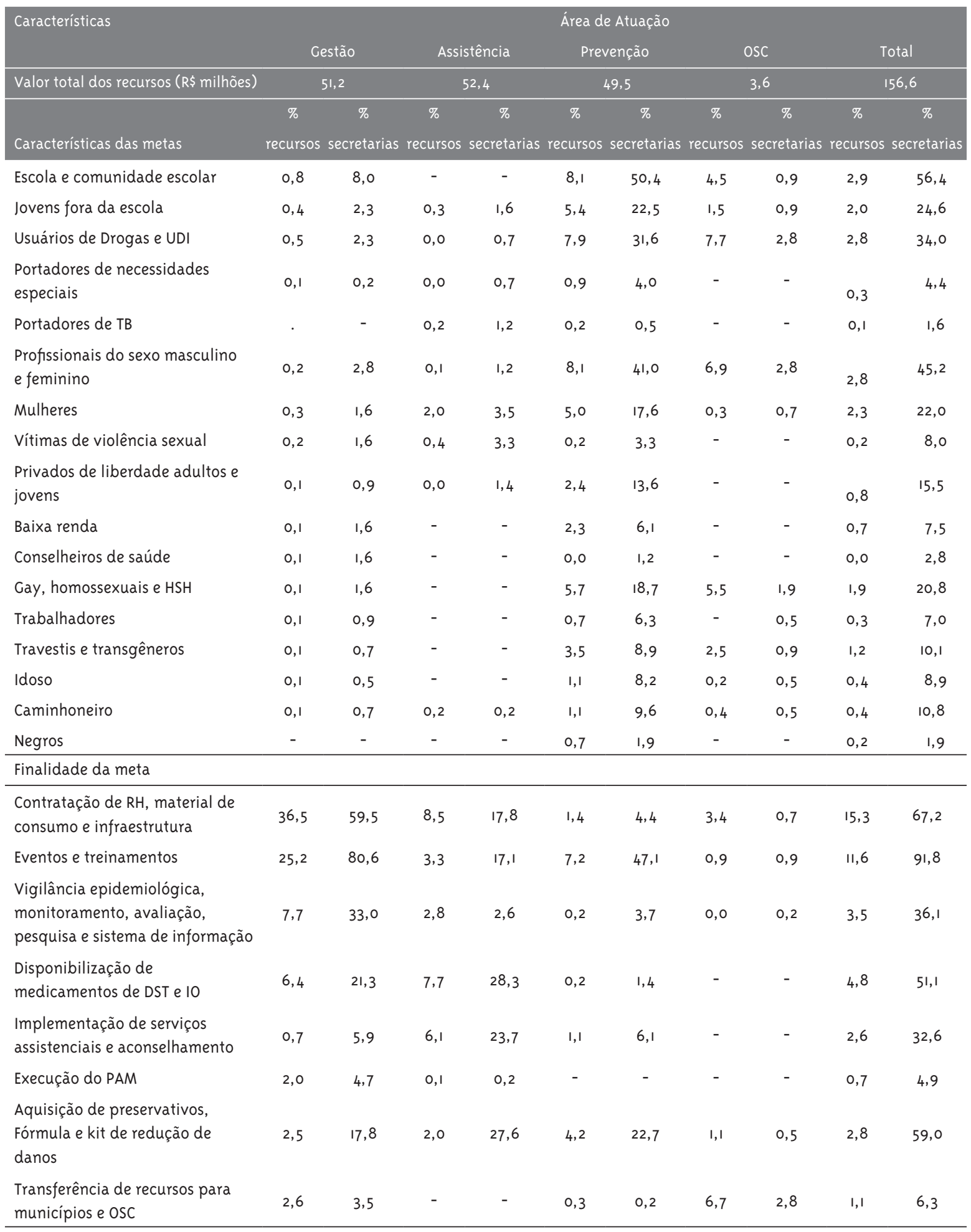


Tabela 3 - Percentual de recursos e de secretarias municipais de saúde qualificadas na Política de Incentivo do Ministério da Saúde para programas de aids segundo características das metas e áreas de atuação. Brasil, 2006 (continuação)

\begin{tabular}{|c|c|c|c|c|c|c|c|c|c|c|}
\hline \multirow{3}{*}{$\begin{array}{l}\text { Características } \\
\text { Valor total dos recursos (R\$ milhões) }\end{array}$} & \multicolumn{10}{|c|}{ Área de Atuação } \\
\hline & \multicolumn{2}{|c|}{ Gestão } & \multicolumn{2}{|c|}{ Assistência } & \multicolumn{2}{|c|}{ Prevenção } & \multicolumn{2}{|c|}{ OSC } & \multicolumn{2}{|c|}{ Total } \\
\hline & \multicolumn{2}{|c|}{51,2} & \multicolumn{2}{|c|}{52,4} & \multicolumn{2}{|c|}{49,5} & \multicolumn{2}{|c|}{3,6} & \multicolumn{2}{|c|}{156,6} \\
\hline & $\%$ & $\%$ & $\%$ & $\%$ & $\%$ & $\%$ & $\%$ & $\%$ & $\%$ & $\%$ \\
\hline Características das metas & recursos & secretar & recurso: & ecretari & recurso & cretar & ecurso & cretar & ecurs & cretari \\
\hline $\begin{array}{l}\text { Ação educativa e distribuição de } \\
\text { preservativo }\end{array}$ & 3,3 & 14,3 & 0,8 & 2,8 & 12,3 & 44,7 & 0,1 & 0,2 & 5,2 & 54,8 \\
\hline $\begin{array}{l}\text { Implantação de serviços } \\
\text { assistenciais e CTA }\end{array}$ & 3,4 & 11,0 & 8,4 & 25,5 & 2,8 & 15,5 & - & - & 4,8 & 43,6 \\
\hline $\begin{array}{l}\text { Implantação de projetos e } \\
\text { programas }\end{array}$ & 3,2 & 10,1 & 10,2 & 30,4 & 22,6 & 60,9 & 0,2 & 0,5 & 11,6 & 74,0 \\
\hline $\begin{array}{l}\text { Atendimento à população, } \\
\text { ampliação de cobertura de ações }\end{array}$ & 2,7 & 4,4 & 29,9 & 66,5 & 9,0 & 47,1 & 0,1 & 0,2 & 13,7 & 82,0 \\
\hline $\begin{array}{l}\text { Parceria com secretarias e outros } \\
\text { órgãos }\end{array}$ & 0,2 & 3,0 & 0,4 & 0,9 & 0,1 & 1,4 & - & - & 0,2 & 4,7 \\
\hline Projetos de OSC & 0,9 & 6,3 & 0,1 & $\mathrm{I}, 2$ & 1,3 & 4,2 & 87,2 & 19,7 & 2,7 & 28,6 \\
\hline $\begin{array}{l}\text { Implantação e melhorias de } \\
\text { laboratórios de DST, aids e } \\
\text { hepatites }\end{array}$ & 1,3 & 2,3 & 8,1 & 26,5 & 1,1 & 10,1 & - & - & 3,5 & 32,3 \\
\hline $\begin{array}{l}\text { Campanhas, material educativo } \\
\text { e outras formas de informação à } \\
\text { população }\end{array}$ & 0,3 & 2,6 & 0,2 & 1,9 & 30,8 & 85,5 & 0,1 & 0,2 & 9,9 & 86,4 \\
\hline Outros & 0,2 & 3,0 & 0,0 & 0,7 & 0,6 & 4,9 & 0,3 & 0,5 & 0,3 & 8,9 \\
\hline Pessoas testadas para o HIV & 0,2 & 1,9 & 11,3 & 20,6 & 4,7 & 15,5 & - & & 5,3 & 36,1 \\
\hline Controle Social & 0,1 & 0,7 & 0,1 & 1,6 & 0,0 & 0,2 & - & - & 0,0 & 1,2 \\
\hline $\begin{array}{l}\text { Normas/protocolos/ } \\
\text { recomendações }\end{array}$ & 0,1 & 1,2 & 8,5 & 17,8 & 0,2 & $\mathrm{I}, 2$ & - & - & 0,1 & 4,0 \\
\hline $\begin{array}{l}\text { Recursos aplicados em ações com } \\
\text { maior poder de intervenção da } \\
\text { epidemia }\end{array}$ & 14,5 & - & 66,8 & - & 53,8 & - & 87,5 & - & 46,1 & - \\
\hline
\end{tabular}


(77,8\%), PVHIV (44,4\%), portadores de DST (37,0\%) e população geral (14,8\%). Somente 90 municípios planejaram metas neste componente, destinando menos de $3 \%$ dos recursos do PAM às OSC (Tabelas 1,2 e 3).

\section{Complexidade programática, inclusão de popula- ções e poder de intervenção na epidemia}

Nessa análise observou-se que a maioria das secretarias apresentou uma complexidade programática parcial (58,6\%), não incluiu as populações prioritárias nas áreas de assistência e prevenção $(67,6 \%)$, realizou gastos majoritários de menor poder de intervenção na prevenção (55,1\%) e não aplicou recursos próprios nas áreas de prevenção e assistência (37,9\%), caracterizando, segundo os critérios desse estudo, um reduzido grau de sustentabilidade financeira local (Tabela 4). Como consequência, 71,1\% das secretarias foram, no contexto da Política de Incentivo, caracterizadas como de "resposta limitada". Esta proporção foi 1,3 vezes maior entre municípios (72,1\%) do que em Estados (55,6\%).

Chama a atenção o fato de que somente 29 municípios (6,8\%) e 7 Estados (25,9\%) apresentaram respostas classificadas como de "maior complexidade", incluindo as 8 ações programáticas consideradas, por este estudo, como essenciais à resposta ao HIV; e que apenas 133 dos municípios (31,1\%) e 14 Estados $(51,9 \%)$ incluíram as populações prioritárias tanto na prevenção, como na assistência (Tabela 4).

As maiores proporções de municípios classificados como de resposta limitada foram observadas no interior do País (75,3\%; Zres:2,1), entre os de pequeno porte, com até 100 mil habitantes $(78,2 \%$; Zres:2,5) e na região Centro Oeste (92,6\%; Zres: 2,5). Ressalta-se, entretanto, que do total dos municípios classificados nessa categoria, 76,3\% estão concentrados no Sul e Sudeste. O valor médio dos PAM dos municípios com resposta limitada equivale a 51,5\% daqueles com resposta abrangente (Tabela 5). Apesar do número reduzido (119; 27,9\%), os municípios com resposta abrangente representaram $48,5 \%$ da população, 56,o\% dos casos de aids ocorridos em cidades incluídas no Incentivo e predominaram em cidades com mais de 200 mil habitantes (Zres:3,0), na região Sudeste (Zres:2,o) e nas capitais (Zres:2,6). $\mathrm{O}$ IDH-M não esteve relacionado às características da resposta municipal (Tabelas 4 e 5).

No âmbito dos Estados, os fatores principais relacionados à limitação da resposta foram a alta proporção de investimento com menor poder de intervenção, a não inclusão de populações prioritárias na assistência e a falta de contrapartida na assistência e prevenção (Tabela 5). Os Estados com respostas limitadas distribuem-se por todas as regiões do País.

\section{Discussão}

A avaliação da Política de Incentivo do Ministério da Saúde mostrou taxas expressivas de cobertura em relação aos casos de aids, evidenciando uma alta capacidade de alocar recursos segundo critérios epidemiológicos. Essa característica é contrária à observada na resposta induzida localmente, que apresentou um caráter limitado e relativamente dissociado do perfil da epidemia no Brasil e das diretrizes do Ministério da Saúde (Brasil, 2002). Isto ocorreu, especialmente, nos municípios do interior do País e naqueles que receberam um menor volume de recursos. Um número reduzido de municípios, porém, caracterizou-se por apresentar uma resposta abrangente e devem ser os principais responsáveis pelos resultados positivos observados na política brasileira (Okie, 2006). Esses municípios estão associados, fundamentalmente, à região Sudeste e aos grandes centros urbanos do País.

As principais restrições da resposta induzida no âmbito da Política de Incentivo assemelharam-se a alguns dos principais desafios da resposta brasileira. Um reduzido número de secretarias propôs, na área de prevenção, ações para o diagnóstico do HIV, a redução do estigma, ações preventivas na assistência e não priorizou populações de maior prevalência.

Ressalta-se que modelos de intervenção centrados na população geral e no aumento do grau de informação têm sido apontados como de menor eficiência para promover mudanças de comportamento, quando comparadas às intervenções em comunidades e voltadas para populações de maior prevalência da doença (Piot e col., 2008; Parker, 2000). Ademais, no Brasil (França Junior e col., 2008), a parcela $(36,4 \%)$ da população que realizou o teste anti-HIV 
Tabela 4 - Número e porcentagem de estados e municípios no contexto da Política de Incentivo do Ministério da Saúde para aids segundo características das ações programáticas. Brasil, 2006

\begin{tabular}{|c|c|c|c|c|c|c|}
\hline \multirow{2}{*}{ Características das ações programáticas } & \multicolumn{2}{|c|}{ Estado e DF } & \multicolumn{2}{|c|}{ Município } & \multicolumn{2}{|c|}{ Total } \\
\hline & $\mathrm{N}^{0}$ & $\%$ & $\mathrm{~N}^{\circ}$ & $\%$ & $\mathrm{~N}^{\circ}$ & $\%$ \\
\hline \multicolumn{7}{|l|}{ Complexidade programática } \\
\hline Complexidade programática parcial & 7 & 25,9 & 259 & 60,6 & 266 & 58,6 \\
\hline Complexidade programática básica & 13 & 48,2 & 139 & 32,6 & 152 & 33,5 \\
\hline Maior complexidade programática & 7 & 25,9 & 29 & 6,8 & 36 & 7,9 \\
\hline \multicolumn{7}{|l|}{ Inclusão de populações prioritárias } \\
\hline Resposta inclusiva na prevenção & 21 & 77,8 & 262 & 61,4 & 283 & 62,3 \\
\hline Resposta inclusiva na assistência & 19 & 70,4 & 199 & 46,6 & 218 & 48,0 \\
\hline Resposta inclusiva na prevenção e assistência & 14 & 51,9 & 133 & 31,1 & 147 & 32,4 \\
\hline \multicolumn{7}{|c|}{ Maior \% de recursos em ações com maior poder de intervenção na epidemia } \\
\hline Na área de prevenção & 11 & 40,7 & 193 & 45,2 & 204 & 44,9 \\
\hline Na área de assistência & 8 & 29,6 & 277 & 64,9 & 285 & 62,8 \\
\hline Nas áreas de prevenção e assistência & 10 & 37,0 & 252 & 59,0 & 262 & 57,7 \\
\hline \multicolumn{7}{|l|}{ Sustentabilidade financeira da Política de Incentivo } \\
\hline Aplicação de recursos próprios na prevenção & 19 & 70,4 & 301 & 70,5 & 320 & 70,5 \\
\hline Aplicação de recursos próprios na assistência & 21 & 77,8 & 343 & 80,3 & 364 & 80,2 \\
\hline Aplicação de recursos próprios prevenção/assistência & 16 & 59,3 & 266 & 62,3 & 282 & 62,1 \\
\hline Respostas abrangentes - Categorias analisadas & 12 & 44,4 & 119 & 27,9 & 131 & 28,6 \\
\hline Complexidade programática básica/maior complexidade & 12 & 100,0 & 87 & 73,1 & 99 & 75,6 \\
\hline Inclusão de populações prioritárias na prevenção & 9 & 75,0 & 108 & 90,8 & 117 & 89,3 \\
\hline Inclusão de populações prioritárias na assistência & 12 & 100,0 & 99 & 83,2 & III & 84,7 \\
\hline $\begin{array}{l}\text { Maior proporção de recursos em ações com maior poder de } \\
\text { intervenção na prevenção e assistência }\end{array}$ & 8 & 66,7 & 104 & 87,4 & 112 & 85,5 \\
\hline Recursos próprios aplicados na prevenção e assistência & 9 & 75,0 & III & 93,3 & 120 & 91,6 \\
\hline Respostas limitadas - Categorias analisadas & 15 & 55,6 & 308 & 72,1 & 323 & 71,1 \\
\hline Complexidade programática básica/maior complexidade & 8 & 53,3 & 81 & 26,3 & 89 & 27,6 \\
\hline Inclusão de populações prioritárias na prevenção & 12 & 80,0 & 154 & 50,0 & 166 & 51,4 \\
\hline Inclusão de populações prioritárias na assistência & 7 & 46,7 & 100 & 32,5 & 107 & 33,1 \\
\hline $\begin{array}{l}\text { Maior proporção de recursos em ações com maior poder de } \\
\text { intervenção na prevenção e assistência }\end{array}$ & 2 & 13,3 & 148 & 48,1 & 150 & 46,4 \\
\hline Recursos próprios aplicados na prevenção e assistência & 7 & 46,7 & 155 & 50,3 & 162 & 50,2 \\
\hline
\end{tabular}

mantém-se inferior à de alguns países de renda alta e média (World Health Organization, 20o8), o que se tem refletido em um número significativo (40,0\%) de pessoas que iniciam o tratamento tardiamente (Souza-Jr e col., 2007). Esse fato pode contribuir para o aumento da incidência e da mortalidade por aids no País (Fischer, 2008).

No que tange ao estigma, inquéritos nacionais
(Garcia e Koyama, 2008) têm observado índices de intenção de discriminação que superam os $90 \%$ em situações envolvendo profissionais do sexo e usuários de drogas. A intenção de discriminação é mais frequente em segmentos sociais que apresentam as maiores taxas de crescimento da doença, como mulheres, indivíduos com menor escolaridade e residentes nas regiões Norte e Nordeste. Esse fato 
Tabela 5 - Valor e porcentagem segundo características dos municípios qualificados e caráter da resposta realizada no âmbito da Política de Incentivo do Ministério da Saúde para aids. Brasil, 2006

\begin{tabular}{|c|c|c|c|c|c|c|c|}
\hline \multirow{3}{*}{ Características } & \multicolumn{6}{|c|}{ Resposta no âmbito da política de incentivo } & \multirow{3}{*}{$p$} \\
\hline & \multicolumn{3}{|c|}{ Abrangente } & \multicolumn{3}{|c|}{ Limitada } & \\
\hline & Valor & $\%$ & Zres & Valor & $\%$ & Zres & \\
\hline \multicolumn{8}{|l|}{ Epidemiologia } \\
\hline Casos de aids 2002 a 2006 & 85982 & 56,0 & - & 67688 & 44,0 & - & $<0,001$ \\
\hline Incidência média (100 mil hab.) & 28,1 & - & - & 25,0 & - & - & 0,048 \\
\hline Valor médio (R\$) aplicado no incentivo & $564.213,95$ & - & - & $290.590,70$ & - & - & $<0,001$ \\
\hline IDH-M médio & 0,795 & - & - & 0,786 & - & - & 0,710 \\
\hline Habitantes (№) & 51.805 .775 & 48,5 & - & 55.119 .127 & 51,5 & - & $<0,001$ \\
\hline $500 \mathrm{mil} \mathrm{ou}+$ & 17 & 48,6 & 2,85 & 18 & 51,4 & $-2,85$ & \\
\hline 200 a $499 \mathrm{mil}$ & 37 & 40,2 & 2,98 & 55 & 59,8 & $-2,98$ & \\
\hline 100 a $199 \mathrm{mil}$ & 24 & 21,4 & $-1,77$ & 88 & 78,6 & 1,77 & \\
\hline Até $99 \mathrm{mil}$ & 41 & 21,8 & $-2,48$ & 147 & 78,2 & 2,48 & \\
\hline \multicolumn{8}{|l|}{ Inserção } \\
\hline Capital & 13 & 50,0 & 2,60 & 13 & 50,0 & $-2,60$ & 0,015 \\
\hline Região Metropolitana & 35 & 31,0 & 0,86 & 78 & 69,0 & $-0,86$ & \\
\hline Interior & 71 & 24,7 & $-2,13$ & 217 & 75,3 & 2,13 & \\
\hline Região Centro Oeste & 2 & 7,4 & $-2,45$ & 25 & 92,6 & 2,45 & $0,050^{*} / 0,027^{* *}$ \\
\hline Goiás & 1 & 12,5 & 0,66 & 7 & 87,5 & $-0,66$ & \\
\hline Mato Grosso do Sul & 1 & 14,3 & 0,81 & 6 & 85,7 & $-0,81$ & \\
\hline Mato Grosso & - & - & $-1,31$ & 12 & 100,0 & 1,31 & \\
\hline Norte & 2 & 14,3 & $-1,15$ & 12 & 85,7 & 1,15 & \\
\hline Acre & - & - & $-0,42$ & 1 & 100,0 & 0,42 & \\
\hline Amazonas & 1 & 50,0 & $-1,56$ & 1 & 50,0 & 1,56 & \\
\hline Amapá & - & - & $-0,42$ & I & 100,0 & 0,42 & \\
\hline Pará & 1 & 20,0 & 0,46 & 4 & 80,0 & $-0,46$ & \\
\hline Rondônia & - & - & $-0,42$ & 1 & 100,0 & 0,42 & \\
\hline Roraima & - & - & $-0,42$ & 1 & 100,0 & 0,42 & \\
\hline Tocantins & - & - & $-0,80$ & 3 & 100,0 & 0,80 & \\
\hline Nordeste & 17 & 30,4 & 0,45 & 39 & 69,6 & $-0,45$ & \\
\hline Alagoas & 1 & 50,0 & $-0,62$ & 1 & 50,0 & 0,62 & \\
\hline Bahia & 5 & 54,5 & $-1,21$ & 6 & 45,5 & 1,21 & \\
\hline Ceará & - & - & $-1,55$ & 5 & 100,0 & 1,55 & \\
\hline Maranhão & 7 & 53,8 & 2,10 & 6 & 46,2 & $-2,10$ & \\
\hline Paraíba & - & - & $-1,55$ & 5 & 100,0 & 1,55 & \\
\hline Pernambuco & 2 & 15,4 & $-1,33$ & II & 84,6 & 1,33 & \\
\hline Piauí & - & - & $-1,37$ & 4 & 100,0 & 1,37 & \\
\hline Rio Grande do Norte & 1 & 50,0 & 0,62 & 1 & 50,0 & $-0,62$ & \\
\hline Sergipe & 1 & 100,0 & 1,53 & - & - & $-1,53$ & \\
\hline
\end{tabular}


Tabela 5 - Valor e porcentagem segundo características dos municípios qualificados e caráter da resposta realizada no âmbito da Política de Incentivo do Ministério da Saúde para aids. Brasil, 2006 (continuação)

\begin{tabular}{lcccccc} 
& \multicolumn{5}{c}{ Resposta no âmbito da política de incentivo } \\
Características & \multicolumn{3}{c}{ Abrangente } & \multicolumn{2}{c}{ Limitada } \\
\cline { 2 - 7 } Sul & Valor & $\%$ & Zres & Valor & $\%$ & Zres \\
\hline Paraná & 24 & 24,5 & $-0,85$ & 74 & 75,5 & 0,85 \\
Rio Grande do Sul & 7 & 26,9 & 0,34 & 19 & 73,1 & $-0,34$ \\
Santa Catarina & 4 & 10,3 & $-2,66$ & 35 & 89,7 & 2,66 \\
\hline Sudeste & 13 & 39,4 & 2,44 & 20 & 60,6 & $-2,44$ \\
\hline Espírito Santo & 74 & 31,9 & 2,02 & 158 & 68,1 & $-2,02$ \\
Minas Gerais & 4 & 36,4 & 0,33 & 7 & 63,6 & $-0,33$ \\
Rio de Janeiro & 8 & 18,6 & $-2,07$ & 35 & 81,4 & 2,07 \\
São Paulo & 12 & 36,4 & 0,59 & 21 & 63,6 & $-0,59$ \\
\hline Brasil & 50 & 34,5 & 1,09 & 95 & 65,5 & $-1,09$ \\
\hline
\end{tabular}

$\left({ }^{*}\right)$ referente à região; $\left({ }^{* *}\right)$ referente aos Estados

torna o fortalecimento das ações de redução do estigma em um elemento estratégico para o controle da epidemia, que permitiria aproximar a resposta de Estados e municípios das diretrizes nacionais e do arcabouço ético e jurídico já constituído no País (Grangeiro e col, 2009; Berkman e col, 2005).

Outro destaque é a baixa inclusão nos PAM de populações de maior prevalência, que apresentam um risco de infecção significativamente superior ao da população geral e colaboram para o aumento dos casos, em diversas categorias de transmissão (Barbosa Junior e col, 2009). Essa ausência de prioridade tem sido recorrente em diversos países (Piot e col, 2008), estando relacionada a fatores sociais que atuam como barreiras de inclusão.

No caso brasileiro, a ausência de prioridade evidencia um paradoxo, pois essas populações tiveram ao longo do tempo um importante papel na reposta à aids; constam como prioridade nas diretrizes do Ministério da Saúde e possuem um intenso ativismo, estando representadas nas instâncias de definição das políticas nacionais (Grangeiro e col., 2009, 2010; Berkman e col., 2005; Okie, 2006). Diversos fatores podem estar contribuindo para esse paradoxo, entre os quais: (a) um modelo de intervenção baseado em um perfil epidemiológico que sobrevaloriza a expansão da epidemia na população geral; (b) a expectativa de que intervenções junto a esses grupos sejam mais bem realizadas por OSC, minimizando a ação direta do Estado; e (c) a suposição de que esses grupos poderiam ter expressivos índices de práticas seguras e amplo acesso aos serviços do SUS.

Em relação à assistência, as principais limitações referem-se à parcela de secretarias que não previram ações de profilaxia da transmissão vertical e o diagnóstico e tratamento das DST. A exclusão dessas ações implica perda de oportunidades para evitar a ocorrência de novos casos de infecção pelo HIV e outros agravos à saúde. No caso da transmissão vertical, a cobertura do diagnóstico do HIV no pré-natal no Brasil é inferior à observada em outros países de renda média, como Argentina e Tailândia (Word Heath Organization, 2008). Por sua vez, as DST são um importante problema de saúde, com prevalência no período estudado (autorreferido) superior a $13 \%$ entre homens de 16 e 65 anos e índices de conhecimento inferiores ao de aids (Bastos e col., 2008). Essas doenças, ainda, têm provocado inúmeras ocorrências clínicas, como esterilidade e câncer. Esses fatos tornam o enfrentamento das DSTs imperativo.

Os estudos (Fonseca e col., 2007; Duarte, 2008) que analisaram o impacto do processo de descentralização das ações de aids nas atividades das OSC mostram como resultado uma possível redução do financiamento para essas instituições. Os dados 
analisados nesta pesquisa não permitiram avaliar este aspecto, pois se concentraram na investigação das características das ações executadas pelas OSC com os recursos da Política de Incentivo e não possuem um caráter histórico. Os achados, porém, mostraram que o financiamento das OSC, no âmbito da Política de Incentivo, permanece restrito aos recursos federais e não ultrapassam a parcela de 10\% do total dos recursos a serem executados. Devido à importância estratégica das OSC, são necessárias medidas para garantir que o processo de descentralização não represente um impacto negativo no curso da epidemia.

Um dos aspectos positivos observados na avaliação é que a Política de Incentivo permite destinar um importante volume de recursos às ações voltadas diretamente à população, caracterizando-a como um instrumento de ampliação do acesso ao SUS. Em relação aos gastos, contudo, chama a atenção o número de secretarias que prioriza ações de menor poder de intervenção na epidemia, assim como a ausência de aquisições de preservativos e medicamentos. Esses itens têm sido objeto de relatos de escassez nos serviços de saúde (Portela e Lotrowska, 2006).

Os achados do presente estudo devem ser interpretados considerando suas limitações. Os PAM são resultantes de um processo de planejamento com a participação de inúmeros atores, o que o torna singular em cada Estado e município. Essa especificidade pode implicar diferentes formas de apresentar as metas, de denominar as populações e de alocar a contrapartida. A análise elaborada buscou minimizar esse efeito, mas é possível que determinadas especificidades não tenham sido captadas ou tenham sido excessivamente homogeneizadas. Ainda, no âmbito local, existe uma multiplicidade de fontes de financiamento não abrangidas pela Política de Incentivo, o que torna a resposta de Estados e municípios mais complexa do que a aqui apresentada. As limitações apontadas na resposta induzida pela Política de Incentivo podem, inclusive, estar sendo objeto de intervenções com outros recursos do SUS e de instituições locais. Os PAM, assim, podem estar refletindo prioridades complementares à resposta local, o que poderia explicar, entre outros aspectos, a ausência de investimentos na prevenção da transmissão vertical e tratamento das DST.
Há que se considerar, entretanto, que a Política de Incentivo possui um importante papel no financiamento e na definição de normas que orientam a organização da resposta local. Os resultados apresentados nos permitem, assim, pela primeira vez, conhecer as características da resposta induzida por este instrumento em Estados e município que são prioritários para o controle da epidemia. Assim, aprimorar os mecanismos de avaliação e aprovação dos PAM apresentados por Estados e municípios e os modelos de intervenção em secretarias com resposta limitada pode colaborar para não tornar crônicas as insuficiências observadas e aumentar o impacto positivo da resposta brasileira.

\section{Agradecimentos}

À equipe da Unidade de Planejamento do Departamento Nacional de DST, Aids e Hepatites Virais, especialmente, Sérgio D`Avila, Maria Alice Tironi e Sandra Regina Miguel, pelas contribuições nas discussões e o fornecimento de informações.

\section{Referências}

BANCO MUNDIAL, DEPARTAMENTO DE AVALIAÇÃO DE OPERAÇÕES. Brasil: primeiro e segundo projetos de controle da aids e DST. Washington, D.C., 2004. p. 81 (relatório de avaliação de desempenho de Projeto). Disponível em: <http://www-wds.worldbank.org/external/ default/WDSContentServer/WDSP/IB/2005/o1/ 03/ooo160016_20050103162746/Rendered/PDF/ pparo28819oportuguese.pdf> Acesso em: 27 out. 2009.

BARBOSA JUNIOR, A. et al. Tendências da epidemia de AIDS entre subgrupos sob maior risco no Brasil, 1980-2004. Cadernos de Saúde Pública, Rio de Janeiro, v. 25, n. 4, 2009, p. 727-737.

BARBOZA, R. Gestão do Programa Estadual DST/ AIDS de São Paulo: uma análise do processo de descentralização das ações no período de 1994 a 2003. Dissertação (Mestrado em Ciências) - Coordenadoria de Controle de Doenças da Secretaria de Estado da Saúde de São Paulo, São Paulo, 2006. 
BASTOS, F. I.; CUNHA, C. B.; HACKER, M. A. Grupo de Estudos em População, Sexualidade e Aids. Sinais e sintomas associados às doenças sexualmente transmissíveis no Brasil, 2005. Revista de Saúde Pública, São Paulo, v. 42, n. supl 1, 2008, p. 98-108.

BERKMAN, A. et al. A critical analysis of the Brazilian response to HIV/AIDS: lessons learned for controlling and mitigating the epidemic in developing countries. American Journal of Public Health, Washington, D.C., v. 95, n. 7, 2005, p. 1162-72.

BRASIL, MINISTÉRIO DA SAÚDE. Portaria No. 2314, de 20 de dezembro de 2002. Aprovar a norma técnica - Incentivo HIV/AIDS e outras DST № 01/2002. Disponível em: <http://www.aids.gov.br/ incentivo/> Acesso em: 27 jan. 2010.

DUARTE, C. A. E. O Paradoxo da descentralização no financiamento para as ações de DST/AIDS: visão das entidades representativas do movimento social em municípios do Rio Grande do Sul. Trabalho de conclusão do curso (Especialização em Saúde Pública) - Universidade Federal do Rio Grande do Sul, Rio Grande do Sul, 2008.

ESCOREL, S. Reviravolta na saúde: origem e articulação do movimento sanitário. Rio de Janeiro: Fiocruz, 1999.

FISHER, M. Late diagnosis of HIV infection: major consequences and missed opportunities. Current Opinion in Infectious Diseases, London, v. 21, n. 1, 2008, p. 1-3.

FONSECA, E. M. et al. Descentralização, AIDS e redução de danos: a implementação de políticas públicas no Rio de Janeiro, Brasil. Cadernos de Saúde Pública, Rio de Janeiro, v. 23, n. 9, 2007, p. 2134-44.

FRANÇA JUNIOR, I.; CALAZANS, G.; ZUCCHI, E. M. Grupo de estudos em população, sexualidade e AIDS. Mudanças no âmbito da testagem anti-HIV no Brasil entre 1998 e 2005. Revista de Saúde Pública, São Paulo, v. 42, n. supl 1, 2008, p. 84-97.

GARCIA, S.; KOYAMA, M. A. H. Grupo de estudos em população, sexualidade e AIDS Estigma, discriminação e HIV/AIDS no contexto brasileiro, 1998 e 2005. Revista Saúde Pública, São Paulo, v. 42, n. supl 1, 2008, p.72-83.
GRANGEIRO, A. et al. Estratégias de descentralização e municipalização da resposta à aids no Brasil: implicações para as secretarias de saúde e organizações não governamentais. Tempus Acta em Saúde Coletiva, Brasília, v. 4, n. 2, 2010, p. 14-33.

GRANGEIRO, A.; LAURINDO DA SILVA, L.; TEIXEIRA, P. R. Resposta à AIDS no Brasil: contribuições dos movimentos sociais e da reforma sanitária. Rev Panam Salud Publica, Washington, D.C., v. 26, n. 1, 2009, p. 87-94.

IBGE - INSTITUTO BRASILEIRO DE GEOGRAFIA E ESTATÍSTICA. <http://www.ibge.gov.br/home/ estatistica/economia/perfilmunic/defaulttab1_ perfil.shtm> Acesso em: 20 dez. 2008.

MINISTÉRIO DA SAÚDE, DEPARTAMENTO DE INFORMÁTICA DO SUS. Informações de Saúde. <http:// http://www2.aids.gov.br/cgi/deftohtm. exe?tabnet/br.def > Acesso em: 19 dez 2008.

OKIE, S. Fighting HIV - lesson from Brazil. New England Journal of Medicine, Boston, v. 354, n. 19, 2006, p. 1977-81.

PARKER, R. Na contramão da Aids: sexualidade, intervenção, política. Rio de Janeiro; São Paulo: ABIA: Editora 34, 2000.

PEREIRA, J. C. R. Bioestatística em outras palavras. $1^{\underline{a}}$ ed. São Paulo: Edusp, 2010.

PIOT, P. et al. Coming to terms with complexity: a call to action for HIV prevention. Lancet, Londres, V. 372, 2008, p. 845-59.

PIRES, D. R. F. Alguns apontamentos sobre o processo de descentralização do programa de AIDS. Dissertação (Mestrado em Saúde Coletiva) - Instituto de Medicina Social da Universidade Federal do Rio de Janeiro, Rio de Janeiro, 2006.

PORTELA, M. C.; LOTROWSKA, M. Assistência aos pacientes com HIV/Aids no Brasil. Revista de Saúde Pública, São Paulo, v. 40, n. supl, 2006, p. 70-79.

PNUD - PROGRAMA DAS NAÇÕES UNIDAS PARA O DESENVOLVIMENTO. Atlas do desenvolvimento humano; 20o7. Disponível em: <http://www.pnud. org.br/atlas/> Acesso em: 18 Jun 2007. 
PROGRAMA NACIONAL DE DST E AIDS. Política de Incentivo. <http://www.aids.gov.br/incentivo/> Acesso em: og fev 2009.

SOUZA-JR, P. R. B.; SZWARCWALD, C.

L.; CASTILHO, E. A. Delay in introducing antiretroviral therapy in patients infected by HIV in Brazil, 2003-2006. Clinics, São Paulo, v. 62, n. 5 , 2007, p. 579-84.

TAGLIETA, M. F. B. Avaliação da implantação do incentivo no âmbito do Programa Nacional de HIV/ AIDS e outras DST em dois municípios do estado de São Paulo. Dissertação (Mestrado profissional em vigilância em saúde e avaliação de programas de controle de processos endêmicos) - Escola Nacional de Saúde Pública. Fundação Oswaldo Cruz, Rio de Janeiro, 2006.

VIANA, A. L. d'A.; MACHADO, C. V.

Descentralização e coordenação federativa: a experiência brasileira na saúde. Ciência \& Saúde Coletiva, Rio de Janeiro, v. 14, n. 3, 2009, p. 807-

817.

WORLD HEALTH ORGANIZATION; JOINT UNITED NATIONS PROGRAMME ON HIV/AIDS; UNITED NATIONS CHILDREN'S FUND. Towards universal access: scaling up priority HIV/aids interventions in the health sector. Geneva, 2009. p. 164 